\title{
Primeiros tempos da saúde pública em São Paulo
}

\author{
Lina Rodrigues de Faria \\ Mestre em saúde coletiva, pesquisadora visitante do \\ Departamento de Pesquisa da Casa de Oswaldo Cruz \\ Av.Brasil, 4365, Prédio do Relógio \\ 21040-360 Rio de Janeiro — RJ Brasil
}

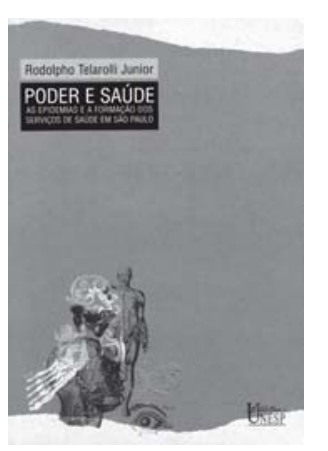

Rodolpho

Telarolli Junior

Poder e saúde: as epidemias e a formação dos serviços de saúde em São Paulo São Paulo, Editora da Unesp, 1996, 259 pp.
$\mathrm{N}$ as duas últimas décadas no Brasil, foram produzidos vários estudos históricos e sociológicos sobre o tema da saúde pública na Primeira República. Esses trabalhos tiveram fundamental importância no desenvolvimento da história da saúde e da ciência no país. Algumas dessas obras constituem leituras obrigatórias para este período de nossa história: os modelos econômicos e políticos, os movimentos pela reforma da saúde e seus líderes, as ideologias da ordem ou de mudança, os diferentes níveis de centralização ou descentralização do poder político, o processo político decisório que produziu instituições de saúde pública no Brasil. Por abordar alguns desses tópicos, Poder e saúde constitui, sem dúvida, uma contribuição importante à literatura republicana.

Rodolpho Telarolli Junior apresenta um estudo sobre a história da saúde pública na Primeira República, em especial, sobre o processo de criação de políticas públicas na área de saúde e a formação das práticas sanitárias no estado de São Paulo, no contexto mais amplo da organização política, econômica e social.

Seu trabalho está construído sobre dois eixos principais de análise. O primeiro refere-se ao estudo da criação de serviços de saúde no estado de São Paulo e o papel desempenhado pela organização política oligárquica nesse processo. O autor analisa os conflitos entre as autoridades sanitárias estaduais e as elites rurais e urbanas no controle de medidas relacionadas à saúde: as mudanças nas orientações políticas, ora com ênfase estadualizante nos movimentos de reforma, ora municipalizante. O segundo eixo diz respeito às relações entre as concepções científicas do final do século XIX e o padrão de organização tecnológica das ações sanitárias.

O marco cronológico que orienta esta obra estende-se do final do século XIX, com a proclamação da República, até 1911, ano da segunda importante reforma do aparelho estadual de saúde pública ocorrida durante a gestão de Emilio Ribas à frente da Diretoria do Serviço Sanitário de São Paulo. Este período seria caracterizado, também, pela consolidação do modelo denominado "campanhista-policial" (E. E. Merhy), que orientou o conjunto das práticas sanitárias implementadas nas primeiras duas décadas da República. Não são estudados, portanto, os modelos que regularam a ação do Estado na saúde nas décadas finais da Primeira República.

Telarolli Junior inicia seu trabalho com um breve balanço da historiografia sobre institucionalização da saúde pública e formação das práticas sanitárias na Primeira República. Na primeira parte do livro, o autor focaliza o impacto da organização política oligárquica sobre a ampliação das políticas de saúde e saneamento no estado de São Paulo. A crescente oligarquização do poder político influenciou significativamente o processo de formação dos serviços 
de saúde nesse estado. Nas palavras do autor, "o federalismo implicou a descentralização para os estados de mais atribuições políticas e administrativas. O maior dinamismo econômico e social do estado de São Paulo fez com que essa descentralização assumisse grandes proporções desde o início da República, incluindo as ações de saúde e saneamento" (p. 77). Para Telarolli Junior, o aumento significativo da intervenção federal na área da saúde, durante a Primeira República, não se verificou em São Paulo.

Ao discutir o modelo político que caracterizou o Estado brasileiro nesta fase republicana, Podere saúde, publicado a partir de sua tese de doutorado, defendida em 1993, se ressente da ausência de uma bibliografia mais extensa sobre o papel do Estado e dos partidos políticos. Uma das lacunas maiores é a ausência das discussões presentes nos trabalhos de Elisa Pereira Reis, em The agrarian roots of authoritarian modernization in Brazil, de 1979, Elites agrárias, statebuilding e autoritarismo, de 1982, Poder privado e construção de Estado na Primeira República, de 1991; e nos textos de Luiz Antonio de Castro Santos, Power, ideology and public health in Brazil: 1889-1930, de 1987, e A reforma sanitária 'pelo alto': o pioneirismo paulista no início do século XX, de 1993.

Elisa Reis analisa o processo político geral na Primeira República, dando destaque particular ao estudo das relações de poder entre Estado e oligarquias agrárias. Em seu trabalho, mostra que a consolidação do poder das oligarquias ao nível local, estadual e até mesmo nacional foi acompanhada de perto pelo crescimento significativo da intervenção federal. Segundo Reis, quanto mais o Estado atendia às demandas das oligarquias agrárias, mais consolidava uma função tutelar sobre a economia.

No caso particular da evolução do setor de saúde, notadamente a partir da década de 1910, Luiz A. de Castro Santos vê nas relações entre o governo estadual de São Paulo e as elites rurais e urbanas um reflexo das relações de poder entre centro e periferia em escala nacional. É o caso, por exemplo, da atuação do Partido Republicano Paulista (PRP) como importante instrumento de articulação dos interesses estaduais e federais. Ainda que Telarolli Junior se limite ao período inicial da Primeira República, os trabalhos citados representam análises diferentes das propostas pelo autor.

Mais recentemente, a tese de doutoramento de Gilberto Hochman, $A$ era do saneamento: as bases da política de saúde pública no Brasil, repõe estas questões. O autor discute a política paulista de saúde pública relacionando-a com o movimento pela reforma sanitária em todo o país e os debates sobre as reformas dos serviços sanitários federais. Para Hochman, as decisões sobre as políticas de saúde, durante a Primeira República, estão associadas às relações entre poder central e oligarquias regionais e aos mecanismos de interdependência que se estabeleciam.

Estes autores, ao abordar o tema das políticas de saúde pública no Brasil, neste período, tratam não apenas das políticas sanitárias implementadas, mas focalizam de perto o papel do Estado nesse processo, das ideologias nacionalistas, das relações entre as oligarquias e os governos, das tradições médicas. Para estes autores, os imperativos da produção econômica não ditavam, de maneira incontestável, o modo pelo qual as políticas de saúde iam se formando no Brasil. As necessidades de exportação da produção cafeeira — o mercado externo — , as próprias necessidades dessa produção quanto às condições de saúde do trabalhador, eram um elemento condicionante, mas não determinante dos serviços de saúde. 
Ainda na primeira parte de sua obra, Telarolli Junior analisa a relação entre febre amarela, imigração e ferrovias. A doença, demonstra o autor, espalhava-se pela região seguindo de perto a trajetória das plantações de café. Outras enfermidades são discutidas, como malária, varíola, cólera e febre tifóide, que monopolizavam as preocupações das autoridades sanitárias estaduais; porém, mais do que qualquer outra, a febre amarela foi, segundo o autor, responsável pelo alto índice de mortalidade entre os imigrantes estrangeiros e a população brasileira, recebendo, portanto, maior atenção dos poderes públicos. "A febre amarela desestabilizava toda a vida política e administrativa, ameaçando as atividades da cafeicultura ... e as demais atividades econômicas urbanas" (p. 237). Outras doenças, como, por exemplo, a tuberculose, foram, segundo o autor, ignoradas pelas autoridades sanitárias estaduais até início da década de 1930, por não representarem uma ameaça imediata ao desenvolvimento da produção agrícola cafeeira.

Para o autor, a imigração estrangeira e o desenvolvimento dos meios de comunicação e transporte foram fatores que influenciaram, significativamente, a formulação das práticas sanitárias estaduais. Nas palavras do autor: "A rapidez nos transportes facilitou a disseminação das epidemias pela zona cafeicultora, levando doentes e vetores a locais ainda não contaminados" (p. 41). O combate às doenças infecciosas teria sido, portanto, o ponto de partida para a transformação e desenvolvimento da medicina em São Paulo. Nesse ponto, podemos dizer que sua análise aproxima-se da tese de Juan César García.

Em seu trabalho sobre o desenvolvimento da medicina estatal na América Latina, García baseia-se numa explicação estrutural-marxista dos processos de reforma sanitária. Nesse processo, destaca-se o papel dinâmico do capitalismo. Quando se refere a São Paulo, afirma que a medicina estatal, ali, modernizouse para se adequar à nova estrutura econômica. A criação de institutos de pesquisa e a produção de novos conhecimentos no campo institucional atendiam os objetivos e interesses econômicos da burguesia cafeicultora.

$\mathrm{Na}$ segunda parte do livro, o autor apresenta os fundamentos tecnológicos que embasaram as ações sanitárias contra as doenças infecciosas, em especial, as campanhas de erradicação da febre amarela em São Paulo. Telarolli Junior recupera os debates científicos da época, sobre os modos de transmissão e difusão das doenças (contágio ou transmissão/ transmissão hídrica ou mista) e as formas de combatê-las.

O modelo de assistência médica e sanitária, que vigorou durante as primeiras décadas da República, tinha como principal característica a adoção de medidas que correspondiam simultaneamente aos dois modelos causais das doenças infecciosas: o contágio e a transmissão. A Diretoria do Serviço Sanitário do Estado de São Paulo dava prioridade tanto à adoção de medidas de prevenção da transmissão - melhoria das condições de higiene e salubridade do meio ambiente, através de obras para canalização de esgotos e abastecimento de água; da inspeção sanitária de casas, fábricas, prisões e hospitais; da fiscalização de alimentos e bebidas — quanto a medidas de combate ao contágio - construção de hospitais de isolamento, desinfecções de casas e roupas —-, além de ações sanitárias de erradicação das epidemias e endemias. A ação estatal no campo da saúde nesse período se voltou, basicamente, segundo o autor, para medidas de controle do espaço urbano. "Essas ações seriam organizadas mediante sua centralização crescente na 
esfera estadual, com o predomínio de ações campanhistas, com intervenções sobre problemas sanitários específicos" (p. 93).

Apesar das várias semelhanças com a medicina praticada durante o Império, as ações sanitárias na Primeira República foram fortemente influenciadas pelas descobertas da bacteriologia. Um dos aspectos privilegiados pela ação estatal, nesse período, foi a substituição de práticas localizadas e temporárias por medidas sanitárias mais permanentes de prevenção e profilaxia das doenças.

Ainda nesta parte do trabalho, Telarolli Junior apresenta informações importantes sobre a resistência popular às medidas higiênicas adotadas pelo Serviço Sanitário paulista. O autor recupera os debates em torno da intervenção do Estado nas questões de saúde versus "restrições às liberdades individuais". Do ponto de vista dos poderes públicos, a ameaça era o doente e não a doença. Em virtude disso, durante os primeiros anos da República, as medidas adotadas pelo Serviço Sanitário buscavam, principalmente, o isolamento do doente do convívio com a sociedade. A assistência médica individual não fazia parte da agenda das práticas sanitárias do modelo "campanhista-policial". As ações sanitárias ficavam restritas às medidas necessárias à erradicação das epidemias.

O cortiço foi, segundo o autor, a habitação popular que mais sofreu repressão por parte dos poderes públicos. Essas moradias eram consideradas "inadequadas do ponto de vista da legislação sanitária" (p. 134) e fonte de propagação de doenças infecciosas. Quando da ocorrência de casos de febre amarela, por exemplo, a atitude do Serviço Sanitário era recorrer à desinfecção dessas habitações ou a sua derrubada. Grande parte dos indivíduos que moravam nos cortiços eram imigrantes estrangeiros que não possuíam moradia permanente. Além das péssimas condições de higiene, a rotatividade das pessoas nessas habitações prejudicava a ação do Serviço Sanitário.

A construção de hospitais de isolamento, outra forma encontrada pelas autoridades sanitárias de combater a propagação das doenças, tinha como principal objetivo o isolamento do doente. Esses hospitais assemelhavam-se aos lazaretos coloniais. "Nos lazaretos coloniais isolavam-se os doentes de lepra, combatendo-se os leprosos e não a doença, objetivando não a cura ou a sua prevenção através da cura, mas somente a retirada do convívio social de seres desviantes que representavam um risco para a coletividade" ( $p$. 150). O tratamento era praticamente inexistente, contribuindo para as altas taxas de mortalidade entre os doentes. Em virtude disso, os hospitais de isolamento eram apontados pela população "como verdadeiras antecâmaras da morte" (p. 155).

Poder e saúde traz fatos poucos explorados pela historiografia, como, por exemplo, a vacinação obrigatória contra a varíola no estado de São Paulo. Segundo Telarolli Junior, a promulgação da lei de obrigatoriedade da vacina nesse estado foi anterior à legislação aplicada ao Rio de Janeiro. Em virtude da pouca resistência da população paulista à vacinação, diferentemente do caso carioca, este episódio não teve grande repercussão como os acontecimentos comumente relacionados à Revolta da Vacina na capital do país.

$\mathrm{Na}$ última parte do livro, o autor apresenta as discussões em torno da organização dos serviços sanitários no estado de São Paulo, mostrando o enorme abismo entre o que determinava a legislação sanitária e as ações concretas no campo da saúde. A defesa da autonomia dos municípios esteve 
sempre presente nos debates parlamentares. De um lado, os dissidentes do PRP, que defendiam a autonomia municipal e as liberdades individuais. De outro, as oligarquias agrárias defensoras de ações sanitárias que visassem, principalmente, a defesa da economia cafeeira. Segundo Telarolli Junior, até o final do século XIX, a ação estadual na área da saúde se voltou quase que exclusivamente para a capital do estado, Santos e Campinas, principais centros econômicos de produção de café. Com a República, tornou-se necessária a organização de um serviço sanitário em São Paulo que desse conta da nova realidade social, econômica e epidemiológica do estado. Uma análise das três importantes reformas da organização do serviço sanitário paulista no final do século XIX — 1892, 1893 e 1896 - mostra as rupturas e continuidades em seus conteúdos e as dificuldades na implantação de uma nova legislação sanitária, em razão das divergências entre o que deveria ser atribuição exclusiva do estado e os limites da autonomia municipal. O primeiro Código Sanitário de São Paulo e as reformas sanitárias de 1906 e 1911 também foram analisados pelo autor. A reforma de 1906 reforçou o modelo centralista de Campos Sales, ampliando o poder estadual sobre as questões de saúde. A reforma de 1911 reverteu esta situação, dando maiores poderes aos municípios em relação à reforma sanitária rural.

Em geral, os trabalhos sobre as políticas de saúde pública no estado de São Paulo não levam em conta as relações entre a política sanitária paulista e os problemas na área da saúde enfrentados pelo governo federal e demais estados brasileiros. As análises ficam restritas ao contexto oligárquico. As políticas de saúde são explicadas, basicamente, como uma transformação necessária à expansão da produção cafeeira.

Telarolli Junior aponta a política estadual de importação de trabalhadores estrangeiros como uma das principais responsáveis pelo desenvolvimento dos serviços sanitários em São Paulo. A proteção aos imigrantes era, segundo o autor, fundamental para o desenvolvimento do setor cafeeiro. Nesse sentido, as ações iniciais de saneamento e controle sanitário buscavam evitar que os trabalhadores nacionais e estrangeiros ficassem vulneráveis às doenças infecciosas. A febre amarela foi alvo prioritário das ações estaduais, pois a saúde pública em São Paulo estaria fortemente vinculada aos interesses da elite cafeicultora.

Ao centralizar sua análise no período inicial da Primeira República (1889 a 1911), o autor apresenta uma versão até certo ponto simplificadora para explicar o desenvolvimento das políticas públicas na área da saúde em São Paulo e o modelo político-partidário que caracterizou a Primeira República. A discussão da política está demasiadamente atrelada à análise da economia, de tal maneira que se poderia dizer que o autor produziu uma obra de qualidade sobre poder econômico e saúde.

Num balanço final, o trabalho de Telarolli Junior apresenta análises históricas cuidadosas baseadas em expressiva documentação. A legislação dos serviços de saúde é um dos pontos fortes do livro. Os hospitais de isolamento e sua relação com as populações locais — seus medos e suas reações — recebem um bom tratamento. O livro é o resultado de um minucioso trabalho de pesquisa e levantamento de fontes documentais. Paralelamente à literatura sobre história da saúde e da ciência no Brasil, o autor privilegiou o uso de fontes primárias, tais como anais, relatórios oficiais, anuários e jornais, buscou ainda conhecer a legislação sanitária estadual, bem como dados demográficos 
relativos ao estado de São Paulo. Dá-se ênfase às diferenças nas taxas de mortalidade por doenças infecciosas na capital e no estado, aos altos índices de mortalidade infantil, à mortalidade em hospitais em São Paulo, durante a Primeira República. Por todos estes motivos, Poder e saúde é certamente uma referência para o leitor que deseja conhecer, mais profundamente, este período de nossa história.

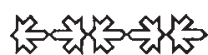

